\title{
DESIGN, OPTIMIZATION, AND STATISTICAL EVALUATION OF ORAL RECONSTITUTED SUSPENSION OF CLARITHROMYCIN USING ION-EXCHANGE RESINS
}

\author{
KOMAL $S^{1 *}$, HARIKRISHNAN N ${ }^{2}$ \\ ${ }^{1}$ Department of Pharmaceutics, Faculty of Pharmacy, Dr. M.G.R. Educational and Research Institute, Chennai, Tamil Nadu, India. \\ ${ }^{2}$ Department of Pharmaceutical Analysis, Faculty of Pharmacy, Dr. M.G.R. Educational and Research Institute, Chennai, Tamil Nadu, India. \\ Email: srikom07@gmail.com
}

Received: 21 November 2019, Revised and Accepted: 08 January 2020

ABSTRACT

Objectives: The objective of the present study is taste masking of bitter clarithromycin using Indion 204, Indion 234 , and Tulsion 335 as ion-exchange resins, which forms insoluble complexes, inhibiting the drug release in saliva as ion-exchange resins are cross-linked polymers, water-insoluble that contains salt-forming groups in repeating positions on the polymer chain. Drugs that are bitter and cationic get adsorbed onto weak cationic exchange resins of carboxylic acid functionality such as Indion 204, Indion 234, and Tulsion 335 to form non-bitter complexes.

Methods: The drug-resin complex loading process was optimized for the resin content, activation, swelling time, stirring time, influence of pH, and temperature for maximum drug loading and the formed complex was evaluated by differential scanning calorimetry (DSC) to confirm complex formation. The drug-resin complex was also characterized by their micromeritic and rheological properties. These complexes were used to prepare oral reconstituted suspensions and the taste was evaluated. The formulation was evaluated for various parameters such as sedimentation volume, $\mathrm{pH}$, redispersibility, viscosity, drug content, and in vitro drug release.

Results: Acid-activated resins comprising Indion 204, Indion 234, and Tulsion 335 with the drug:resin ratio of 1:2, stirred in a solution of pH 7-8 at $70^{\circ}$ for $6 \mathrm{~h}$ had a maximum drug loading and masked the bitter taste of clarithromycin. DSC of the drug-resin complex (DRC) revealed that there was interaction leading to complex formation. The drug-resin complex was formulated into suspension formulations (S1-S9) and evaluated. Various parameters were found to be within permissible limits. Formulations S3, S6, and S9 containing 1:2 ratios of the drug-resin complex of Indion 204, Indion 234, and Tulsion 335 revealed maximum taste masking. This was further confirmed by treatment of taste evaluation scores obtained from the volunteers by ANOVA, Dunnett's multiple comparison test, and Tukey's multiple comparison test. All the three optimized formulations had a significant difference of $\mathrm{p}<0.001$ when compared to control S10. S6 formulation was widely accepted.

Conclusion: Ion-exchange complexation could efficiently mask the bitter taste of clarithromycin and achieve palatable taste suitable for pediatric use.

Keywords: Ion-exchange resins, Drug-resin complex, Taste masking, Indion 204, 234, Tulsion 335, Dunnett's test, Tukey's test, ANOVA.

(C) 2020 The Authors. Published by Innovare Academic Sciences Pvt Ltd. This is an open access article under the CC BY license (http://creativecommons. org/licenses/by/4. 0/) DOI: http://dx.doi.org/10.22159/ajpcr.2020.v13i3.36438

\section{INTRODUCTION}

The ease of administration is the criterion for the preference of oral dosage forms. The bitterness of active pharmaceutical ingredients (API) is one of the significant issues of the pharmaceutical industry during the formulation of dosage form, thereby leading to poor patient compliance. A majority of drugs are bitter due to the presence of amine functional groups, thereby rendering unpleasant taste to the formulation [1]. Hence, it becomes a challenge to the formulator to ensure that the bitterness and obnoxious taste of drugs is masked particularly in pediatric and geriatric formulations dosage form thereby ensuring that the formulation is patient compliant and has product value [2].

Ion-exchange resins are economical and can be incorporated in the development of a basic, rapid, and profitable method of taste masking [3]. Ion-exchange resins are polymeric cross-linkage chains containing salt forming groups in repeating position, which have an affinity for oppositely charged counter ions, thus adsorbing and binding the ions into the polymer matrix in an equilibrium process. The bound drug is desorbed or eluted from the drug-resin complex during the process of absorption into the body $[4,5]$. The versatility of IER as drug delivery vehicles has attracted pharmaceutical research [6]. Ion-exchange resins are used for masking of taste, sustained release, targeted drug delivery, and drug stabilization [7]. Weak cationic exchange resin of carboxylic acid is used for masking bitter cationic drugs to form a non-bitter complex [8].
Clarithromycin is a macrolide antibiotic used in the treatment of common pediatric infections of the middle ear and upper respiratory tract as well as certain forms of pneumonia that affect the elderly [9]. However, the drug is very bitter making oral administration of the drug [10]. It is a practically water-insoluble drug and shows polymorphism and the problem of stability by hydrolysis when it is in a liquid formulation for a long time [10]. Commercially, it is available as a tablet and suspensions but these formulations possess a problem of drug release in the saliva. Hence, it is an objective of the present research to provide an oral reconstituted suspension of clarithromycin which can deliver pharmaceutically acceptable and stable dosage form of API and provides the public with a useful and economic formulation.

\section{MATERIALS AND METHODS}

\section{Materials}

Clarithromycin was obtained as a gift sample from Ind-Swift Laboratories Limited, Punjab. Indion 204 and Indion 234 were gifted by Ion Exchange India Ltd., Mumbai. Tulsion-335 was gifted by Thermax Ltd., Pune. Xanthan gum was obtained from HiMedia, Mumbai. Sodium Benzoate, sucrose, sodium citrate, and flavor were purchased from S.D Fine-Chem. Ltd., Mumbai. Aspartame was purchased from NutraSweet Company and all the chemicals were used of either pharma or analytical grade. 
Taste evaluation of formulation was performed by volunteers within the age group of 21-25 years. Prior explanation of the study protocol and written consent was obtained from the volunteers [11].

\section{Methods}

Standard calibration curve of clarithromycin

The samples of different concentrations of range $20-120 \mu \mathrm{g} / \mathrm{mL}$ were prepared with chloroform. To $10 \mathrm{~mL}$ of each dilution taken in separating funnel, $5 \mathrm{~mL}$ concentrated hydrochloric acid was added followed by $10 \mathrm{~mL}$ of acetone and reaction mixture was shaken gently for $5 \mathrm{~min}$ for the formation of a stable orange-colored complex [12]. The upper orange-red colored layer was separated and the absorbance measured at $486 \mathrm{~nm}$ against reagent blank [12]

\section{Complexation with ion-exchange resin}

Optimization of drug-resin complexation

The loading of the drug onto the resin was optimized for various parameters during processing, including activation conditions, swelling time, stirring time, $\mathrm{pH}$, temperature, and drug:resin ratio [13].

Effect of activation conditions on resin drug loading capacity Activation of Indion 204, Indion 234, and Tulsion 335 was done by washing the individual resins with deionized water, $1 \mathrm{~N} \mathrm{HCl}$ and $1 \mathrm{~N}$ $\mathrm{NaOH}$ in separate processes. The resin was further subjected to repeated washing with water until neutral $\mathrm{pH}$ was reached. Drug-resin complexes (DRC) were prepared by adding $100 \mathrm{mg}$ of activated resin that was swollen for $45 \mathrm{~min}$ into a beaker containing $50 \mathrm{~mL}$ of distilled water and $100 \mathrm{mg}$ of the drug. The mixture was prepared as a slurry with the aid of magnetic stirrer for $6 \mathrm{~h}$ at $60^{\circ} \mathrm{C}$. The residue of the mixture was washed with $100 \mathrm{~mL}$ of chloroform and filtered. From this solution, $0.5 \mathrm{~mL}$ was taken and diluted to $10 \mathrm{~mL}$ with chloroform. The unbound amount drug in the filtrate was estimated spectrophotometrically at $\lambda_{\max } 486 \mathrm{~nm}[12,13]$.

Optimization of resin concentration for maximum drug loading Acid activated swollen resins and drugs were added in the ratio of 1:1, 1:1.5, and 1:2-100 $\mathrm{mL}$ of deionized water in separate beakers and stirred using a magnetic stirrer for $6 \mathrm{~h}$ at $60^{\circ} \mathrm{C}$. The mixture residues were filtered and were washed with chloroform. The drug-loading efficiency of the resin was estimated $[12,13]$.

The optimized resin concentration for the maximum loading of the drug was estimated spectrophotometrically (Table 1).
Optimization of swelling time of resin for maximum drug loading Various batches of acid-activated resins were soaked in $100 \mathrm{~mL}$ quantity of deionized water for $10,20,30,40,50,60$, and $70 \mathrm{~min}$ at $60^{\circ} \mathrm{C}$ temperature in separate beakers. To each beaker drug and resin were added at $1: 2$ ratio and mixtures were stirred for $6 \mathrm{~h}$ at $60^{\circ} \mathrm{C}$. Resin drug-loading efficiency was estimated $[12,13]$. The optimized swelling time of resin required for maximum drug loading was estimated spectrophotometrically (Table 2).

Optimization of stirring time for maximum drug loading 1:2 ratio of drug-resin complexes of separate batches was slurred in $100 \mathrm{~mL}$ of deionized water for $30,60,120,180,240,300$, and 360 min with the aid of magnetic stirrer at $60^{\circ} \mathrm{C}$. Resin drug-loading efficiency was estimated $[12,13]$. The optimized stirring time required for maximum drug loading was estimated spectrophotometrically (Table 2).

Optimization of processing temperature for maximum drug loading 1:2 ratio of drug-resin complexes of separate batches was slurred in $100 \mathrm{~mL}$ of deionized water at different temperatures, namely, $25^{\circ}, 30^{\circ}$, $40^{\circ}, 50^{\circ}, 60^{\circ}$, and $70^{\circ} \mathrm{C}$ using temperature controlled magnetic stirrer for $6 \mathrm{~h}$. The amount of resin drug-loading efficiency was estimated spectrophotometrically from the bound drug. The optimized processing temperature was obtained $[12,13]$ (Table 3 ).

Optimization of $\mathrm{pH}$ for maximum drug loading

1:2 ratio of drug-resin complexes of separate batches were slurred in $100 \mathrm{~mL}$ of standard solutions of hydrochloric acid and sodium hydroxide having $\mathrm{pH} 1.2,2,5,6,7$, and 8 and stirred using a magnetic stirrer for $6 \mathrm{~h}$ at $60^{\circ} \mathrm{C}$. The drug-loading efficiency was estimated and $\mathrm{pH}$ was optimized for maximum drug loading $[12,13]$ (Table 3 ).

\section{Preparation of drug-resin complexes}

Based on optimization study results, batches of drug-resin complexes at 1:1,1:1.5, and 1:2 ratio were prepared at optimized conditions for maximum loading capacity and subjected to further evaluation [13].

Evaluation of the optimized drug-resin complexes for drug content The drug content was determined by eluting the $250 \mathrm{mg}$ of DRC with continuous stirring in $100 \mathrm{~mL} 1 \mathrm{~N} \mathrm{HCl}$ for $1 \mathrm{~h}$ to ensure complete elution [13]. The solution was filtered. After suitable dilution, the drug content was determined spectrophotometrically at $\lambda_{\max } 486 \mathrm{~nm}$ and the readings were taken in triplicate.

Table 1: Effect of activation conditions and resin concentration for maximum drug loading

\begin{tabular}{|c|c|c|c|c|c|c|}
\hline \multirow[t]{2}{*}{ Resins } & \multicolumn{3}{|c|}{$\begin{array}{l}\text { Percentage of drug bound to resin in various } \\
\text { activation conditions (\%) }\end{array}$} & \multicolumn{3}{|c|}{ Percentage of drug bound to various resins (\%) } \\
\hline & Inactivated & Acid & Base & $1: 1$ & 1:1.5 & $1: 2$ \\
\hline Indion 204 & $45.26 \pm 0.68$ & $66.92 \pm 0.83$ & $52.16 \pm 0.34$ & $67.15 \pm 0.28$ & $75.01 \pm 0.40$ & $86.67 \pm 0.26$ \\
\hline Indion 234 & $44.59 \pm 0.77$ & $66.30 \pm 0.72$ & $50.54 \pm 0.64$ & $67.87 \pm 0.56$ & $75.01 \pm 0.29$ & $86.81 \pm 0.36$ \\
\hline Tulsion 335 & $44.30 \pm 0.48$ & $67.06 \pm 0.39$ & $50.73 \pm 0.65$ & $70.01 \pm 0.63$ & $77.39 \pm 0.58$ & $87.14 \pm 0.45$ \\
\hline
\end{tabular}

Results are mean \pm standard deviation $(\mathrm{n}=3)$

Table 2: Optimization of swelling time and stirring time for maximum drug loading

\begin{tabular}{|c|c|c|c|c|c|c|c|}
\hline \multirow[t]{2}{*}{ Swelling time (min) } & \multicolumn{3}{|c|}{$\begin{array}{l}\text { Percentage of drug bound to various } \\
\text { resins (\%) }\end{array}$} & \multirow[t]{2}{*}{ Stirring time (min) } & \multicolumn{3}{|c|}{$\begin{array}{l}\text { Percentage of drug bound to various } \\
\text { resins }(\%)\end{array}$} \\
\hline & Indion 204 & Indion 234 & Tulsion 335 & & Indion 204 & Indion 234 & Tulsion 335 \\
\hline 10 & $70.72 \pm 0.32$ & $65.49 \pm 0.17$ & $66.20 \pm 0.69$ & 30 & $60.73 \pm 0.62$ & $58.58 \pm 0.89$ & $60.25 \pm 0.88$ \\
\hline 20 & $79.29 \pm 0.94$ & $75.86 \pm 0.75$ & $70.96 \pm 0.64$ & 60 & $65.96 \pm 0.36$ & $65.49 \pm 0.98$ & $66.20 \pm 0.35$ \\
\hline 30 & $80.19 \pm 0.17$ & $79.81 \pm 0.98$ & $78.43 \pm 0.76$ & 120 & $71.20 \pm 0.55$ & $70.82 \pm 0.79$ & $70.96 \pm 0.48$ \\
\hline 40 & $83.67 \pm 0.70$ & $83.05 \pm 0.37$ & $83.14 \pm 0.47$ & 180 & $76.91 \pm 0.88$ & $74.86 \pm 0.97$ & $75.01 \pm 0.68$ \\
\hline 50 & $85.91 \pm 0.67$ & $85.29 \pm 0.87$ & $86.62 \pm 0.39$ & 240 & $80.72 \pm 0.69$ & $79.62 \pm 0.78$ & $79.29 \pm 0.46$ \\
\hline 60 & $86.91 \pm 0.46$ & $85.29 \pm 0.62$ & $87.86 \pm 0.63$ & 300 & $84.76 \pm 0.46$ & $83.43 \pm 0.69$ & $82.62 \pm 0.73$ \\
\hline 70 & $86.91 \pm 0.59$ & $85.29 \pm 0.69$ & $88.1 \pm 0.78$ & 360 & $86.67 \pm 0.78$ & $85.81 \pm 0.87$ & $86.19 \pm 0.61$ \\
\hline
\end{tabular}

Results are mean \pm standard deviation $(\mathrm{n}=3)$ 
Evaluation of the prepared drug-resin complexes for drug release The drug release studies were performed by the USP Type XXIII tablet dissolution apparatus. DRC equivalent to $250 \mathrm{mg}$ of clarithromycin was taken in $900 \mathrm{~mL}$ of $0.1 \mathrm{~N} \mathrm{HCl}$. The temperature and speed of the apparatus were maintained at $37 \pm 0.5^{\circ} \mathrm{C}$ and $75 \mathrm{rpm}$, respectively. Aliquots were withdrawn after every $2 \mathrm{~min}$ for $30 \mathrm{~min}$ and were filtered with Whatman filter paper no. 41 and were analyzed spectrophotometrically at $\lambda_{\max } 486 \mathrm{~nm}$. Triplicate readings were taken $[13,14]$.

Differential scanning calorimetry (DSC) was carried out for the characterization of the complex formed. All the DRCs were subjected to DSC and the thermograms were studied for drug-polymer complex formation [13-15].

Micromeritics: The DRCs were evaluated for the angle of repose, Carr's index, tapped and bulk density, and Hausner's ratio [13].

Formulation of the prepared drug-resin complexes into dry powder suspension

Accurately weighedamounts of the prepared complexes of clarithromycin resinates (Indion 204, Indion 234, and Tulsion 335) at 1:1, 1:1.5, and 1:2 drug:resin ratios equivalent to $250 \mathrm{mg}$ of clarithromycin were mixed with other excipients such as suspending agents, sweetener, flavoring agent, preservative, anti-caking agent, and buffer by conventional technique $[16,17]$. All the ingredients were passed through $44 \#$ and mixed. The dry suspension is reconstituted up to $100 \mathrm{ml}$ with distilled water before use. The formulations S1-S9 represented with DRC and S10 represented without DRC (Table 4).

\section{Evaluation parameters}

The angle of repose, Carr's index, as well as the Hausner's ratio for drug powder and dry powder suspension, were determined and compared [13].

Evaluation of the prepared oral reconstituted suspensions $100 \mathrm{~mL}$ of a reconstituted oral suspension of clarithromycin was prepared and fully evaluated for color and odor, viscosity, $\mathrm{pH}$, sedimentation rate, redispersibility, and particle size [16-18].
Furthermore, drug content, drug leaching into the suspension, and in vitro dissolution studies of the drug from the prepared suspensions were determined and compared [17-19].

Assessment of the bitter taste of drug (bitterness threshold)

The bitter taste threshold value of clarithromycin was determined based on the bitter taste recognized by six volunteers. Before measurement, informed written consent was taken from each volunteer [20].

Various concentrations $(10-100 \mu \mathrm{g} / \mathrm{mL})$ of the drug were prepared in phosphate buffer $\mathrm{pH}$ 6.7. The buffer solution was used for rinsing the mouth and then, $10 \mathrm{~mL}$ of the most dilute solution was swirled in the mouth near the base of the tongue for $30 \mathrm{~s}$ and tasted. After $30 \mathrm{~s}$, if the bitter sensation was no longer felt in the mouth, the solution was spat out and wait for $1 \mathrm{~min}$ to ascertain whether this is due to delayed sensitivity. Then rinse with safe drinking water. The recording was.
"-" = Did not detect any difference in taste
"+" = Detected some difference but was not able to specify about the taste and
$"++"=$ Detected a bitter taste.

The next highest concentration should not be tasted until at least $10 \mathrm{~min}$ have passed. The threshold of the bitterness of the drug is defined as the concentration at which more than half of the volunteers detected bitterness when holding the drug in their mouth. The threshold value was correspondingly selected from the different drug concentrations as the lowest concentration that had a bitter taste [21] (Table 5).

\section{In vivo evaluation of the bitter taste of the formulations}

Gustatory sensation tests of prepared suspensions were done using the equivalent density examination method [21]. The pure drug formulation was kept as control during the study. Before the experiment, the study protocol was explained and written consent was obtained from volunteers ( $n=6$; three males and three females). Prepared formulae were kept in the mouth by each volunteer and the bitterness level was recorded against a standard using a numerical scale. The standard quinine hydrochloride concentrations used were $0.01,0.03,0.10,0.30$,

Table 3: Optimization of processing temperature and $\mathrm{pH}$ for maximum drug loading

\begin{tabular}{|c|c|c|c|c|c|c|c|}
\hline \multirow[t]{2}{*}{ Temperature $\left({ }^{\circ} \mathrm{C}\right)$} & \multicolumn{3}{|c|}{ Percentage of drug bound to various resins (\%) } & \multirow[t]{2}{*}{ pH } & \multicolumn{3}{|c|}{ Percentage of drug bound to various resins (\%) } \\
\hline & Indion 204 & Indion 234 & Tulsion 335 & & Indion 204 & Indion 234 & Tulsion 335 \\
\hline 25 & $74.25 \pm 0.69$ & $72.82 \pm 0.58$ & $74.25 \pm 0.53$ & 1.2 & $49.26 \pm 0.86$ & $48.07 \pm 0.38$ & $54.74 \pm 0.57$ \\
\hline 30 & $76.87 \pm 0.47$ & $74.9 \pm 0.46$ & $74.97 \pm 0.58$ & 2 & $54.50 \pm 0.35$ & $51.17 \pm 0.55$ & $59.26 \pm 0.78$ \\
\hline 40 & $79.73 \pm 0.53$ & $78.06 \pm 0.73$ & $80.44 \pm 0.33$ & 5 & $68.30 \pm 0.35$ & $68.30 \pm 0.59$ & $75.92 \pm 0.77$ \\
\hline 50 & $82.34 \pm 0.98$ & $82.87 \pm 0.59$ & $83.06 \pm 0.98$ & 6 & $76.63 \pm 0.65$ & $75.20 \pm 0.87$ & $79.25 \pm 0.46$ \\
\hline 60 & $86.39 \pm 0.53$ & $85.77 \pm 0.28$ & $86.39 \pm 0.46$ & 7 & $86.15 \pm 0.69$ & $84.01 \pm 0.59$ & $85.44 \pm 0.68$ \\
\hline 70 & $89.48 \pm 0.27$ & $87.72 \pm 0.85$ & $88.77 \pm 0.92$ & 8 & $88.53 \pm 0.58$ & $86.39 \pm 0.66$ & $87.58 \pm 0.35$ \\
\hline
\end{tabular}

Table 4: Formulation table for oral reconstituted suspension

\begin{tabular}{|c|c|c|c|c|c|c|c|c|c|c|c|}
\hline \multirow[t]{2}{*}{ S. No. } & \multirow[t]{2}{*}{ Ingredients } & \multicolumn{10}{|c|}{ Gram per tablet } \\
\hline & & S1 & S2 & S3 & S4 & S5 & S6 & S7 & S8 & S9 & S10 \\
\hline 1. & Drug* & - & - & - & - & - & - & - & - & - & $250 \mathrm{mg}$ \\
\hline 3. & DRC Indion 234 & - & - & - & 6.94 & 7.91 & 8.42 & - & - & - & - \\
\hline 4. & DRC Tulsion 335 & - & - & - & - & - & - & 6.66 & 7.81 & 8.42 & - \\
\hline 5. & Xanthan gum & 0.3 & 0.3 & 0.3 & 0.3 & 0.3 & 0.3 & 0.3 & 0.3 & 0.3 & 0.3 \\
\hline 6. & Sodium benzoate & 0.1 & 0.1 & 0.1 & 0.1 & 0.1 & 0.1 & 0.1 & 0.1 & 0.1 & 0.1 \\
\hline 7. & Aspartame & 1.25 & 1.25 & 1.25 & 1.25 & 1.25 & 1.25 & 1.25 & 1.25 & 1.25 & 1.25 \\
\hline 8. & Aerosil & 0.5 & 0.5 & 0.5 & 0.5 & 0.5 & 0.5 & 0.5 & 0.5 & 0.5 & 0.5 \\
\hline 9. & Sodium citrate & 0.3 & 0.3 & 0.3 & 0.3 & 0.3 & 0.3 & 0.3 & 0.3 & 0.3 & 0.3 \\
\hline 10. & Sucrose & 2.13 & 1.42 & 0.60 & 1.60 & 0.63 & 0.12 & 1.89 & 0.74 & 0.12 & 6.05 \\
\hline 11. & Total weight* & 11 & 11 & 11 & 11 & 11 & 11 & 11 & 11 & 11 & 11 \\
\hline 12. & Lake sunset yellow & q.s & q.s & q.s & q.s & q.s & q.s & q.s & q.s & q.s & q.s \\
\hline 13. & Flavor & $1 \mathrm{ml}$ & $1 \mathrm{~m}$ & $1 \mathrm{ml}$ & $1 \mathrm{ml}$ & $1 \mathrm{ml}$ & $1 \mathrm{ml}$ & $1 \mathrm{ml}$ & $1 \mathrm{ml}$ & $1 \mathrm{ml}$ & $1 \mathrm{ml}$ \\
\hline
\end{tabular}

Dose of clarithromycin* - $125 \mathrm{mg} / 5 \mathrm{~mL}$. DRC: Drug-resin complex. ${ }^{*}$ Reconstituted with $100 \mathrm{~mL}$ of water at the time of use 
and $1.00 \mathrm{mM}$ and the corresponding bitterness scores were defined as $0,1,2,3$, and 4, respectively. Before testing, the volunteers are given the standard quinine solutions and asked to swirl in their mouths and were told the concentrations and bitterness scores of each solution [22]. After tasting a test formulation suspended in water, they were asked to give the sample a bitterness score in comparison to the standard. All samples were kept in the mouth for $15 \mathrm{~s}$. After testing the sample, the volunteers rinsed their mouths well and waited for at least $20 \mathrm{~min}$ before tasting the next sample. The average scores for bitterness, flavor, mouthfeel, and overall acceptability for each formulation were calculated and also the standard deviation was arrived (Table 6).

\section{Statistical analysis}

The scores were then interpreted by one-way ANOVA [23] using GraphPad Prism Version 5.0 Software. Dunnett's multiple comparison test was used for comparing all the formulations (S1-S9) with the control formulation (S10). The statistical significance was then interpreted. Tukey's multiple comparison tests are used for comparing the scores within the groups with different ratios of the same resins, and then the formulations having the highest significance levels from each group were compared [24].

\section{RESULTS AND DISCUSSION}

Optimization of drug-resin complexation and resin concentration for maximum drug loading is presented in Table 1. Optimization of swelling time and stirring time of resin for maximum drug loading is shown in Table 2. Optimization of processing temperature and $\mathrm{pH}$ for maximum drug loading is presented in Table 3 . The loading capacity of the resin for clarithromycin was higher in the acid-activated condition when compared to alkaline conditions. This could be explained by the stoichiometric exchange nature reaction between drug and resin in solution. All resins displayed an increase in drug loading capacity with an increase in swelling time. It was found that as the time of stirring of the solution increased, the drug loading also increased and maximum drug loading was achieved within $6 \mathrm{~h}$.

The effect of temperature for optimization is necessary, as, at higher temperatures, the ion diffusion increased. The percent drug-loaded increased with the rise in $\mathrm{pH}$, which was due to the nature of the used resins and drug where the ionization was favored at $\mathrm{pH}$ 8. DRC

Table 5: Determination of bitterness threshold of clarithromycin

\begin{tabular}{lllllll}
\hline \multirow{2}{*}{ Concentration $(\boldsymbol{\mu g} / \mathbf{m l})$} & \multicolumn{7}{l}{ Volunteers } \\
\cline { 2 - 7 } & $\mathbf{1}$ & $\mathbf{2}$ & $\mathbf{3}$ & $\mathbf{4}$ & $\mathbf{5}$ & $\mathbf{6}$ \\
\hline 10 & - & - & - & - & - & - \\
20 & - & - & - & - & - & - \\
30 & - & - & - & - & - & - \\
40 & - & - & - & - & - & - \\
50 & - & - & - & - & + & + \\
60 & + & + & - & - & + & + \\
70 & + & + & - & + & + & + \\
80 & + & + & + & + & + & + \\
90 & + & ++ & + & + & ++ & + \\
100 & ++ & ++ & ++ & ++ & ++ & ++ \\
\hline
\end{tabular}

-Non bitter, +bitter, ++threshold bitterness

Table 6: Preference points for standard bitterness and palatability

\begin{tabular}{llll}
\hline Score & Mouthfeel & Flavor & Overall acceptability \\
\hline 0 & No & No & No \\
1 & Gritty & Poor & Poor \\
2 & Smooth & Acceptable & Acceptable \\
3 & Creamy & Good & Good \\
4 & Very creamy & Very good & Very good \\
\hline
\end{tabular}

comprising Indion 204, Indion 234, and Tulsion 335 at maximum drug-resin ratio (1:2) exhibited drug content in a range of $92.10 \pm 0.59 \%$, $89.01 \pm 0.55 \%$, and $89.01 \pm 0.46 \%$, respectively, and faster dissolution when compared to the pure drug (Fig. 1)

DSC thermograms of drug, resin, and DRC are depicted in Fig. 2.

DRC displayed good micromeritic properties with the angle of repose ranging from $26^{\circ} 12 \pm 0.57$ to $29^{\circ} 38 \pm 0.47$, bulk density values of $0.419 \pm 0.01-0.472 \pm 0.01 \mathrm{~g} / \mathrm{cm}^{3}$, tapped density of $0.505 \pm 0.07$ $0.575 \pm 0.07 \mathrm{~g} / \mathrm{cm}^{3}$, percent compressibility index of $13.461 \pm 0.89$ $17.913 \pm 0.73$, and Hausner's ratio of $1.155 \pm 0.08-1.218 \pm 0.07$. Drypowder suspension parameters were evaluated. The powder displayed angle of repose from $22^{\circ} 59 \pm 0.88$ to $25^{\circ} 69 \pm 0.73$, bulk density of $0.442 \pm 0.01$ $0.479 \pm 0.04 \mathrm{~g} / \mathrm{cm}^{3}$, tapped density of $0.52 \pm 0.06-0.541 \pm 0.07 \mathrm{~g} / \mathrm{cm}^{3}$, percent compressibility index values from $10.800 \pm 0.69$ to $15.163 \pm 0.55$, and Hausner's ratio ranging from $1.121 \pm 0.06$ to $1.78 \pm 0.07$. The dry powder displayed good micromeritic properties with the angle of repose ranging from $22^{\circ} 59 \pm 0.88$ to $25^{\circ} 69 \pm 0.73$, bulk density values of $0.442 \pm 0.01-0.479 \pm 0.04 \mathrm{~g} / \mathrm{cm}^{3}$, tapped density of $0.520 \pm 0.06-$ $0.543 \pm 0.08 \mathrm{~g} / \mathrm{cm}^{3}$, percent compressibility index of $10.800 \pm 0.69$ $15.163 \pm 0.55$, and Hausner's ratio of $1.121 \pm 0.06-1.160 \pm 0.08$.

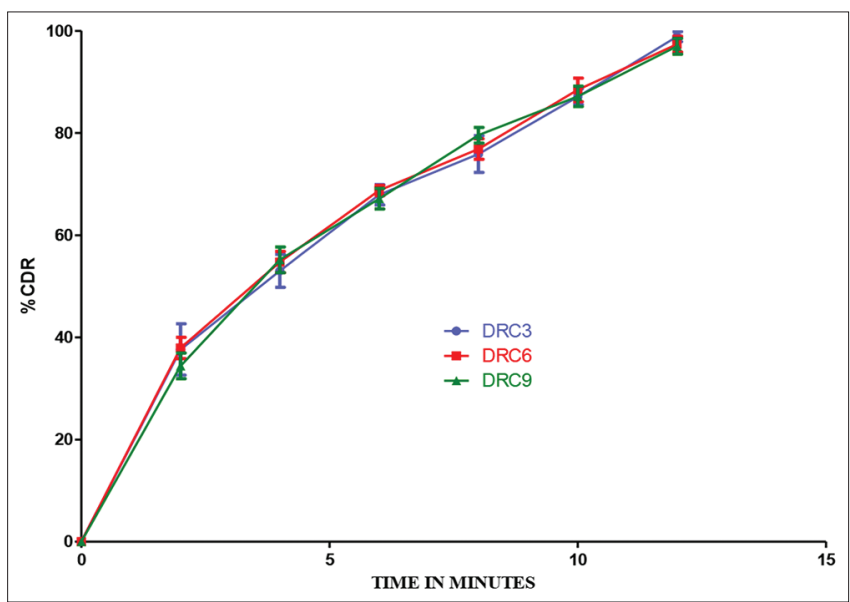

Fig. 1: In vitro dissolution release profiles of resin complex exhibiting maximum drug release. Errors bars represent the standard deviation of $n=3$, DRC3 (drug-resin complex 3-Indion 204) (-๑); DRC6 (drug-resin complex 6-Indion 234) (一匹); DRC9 (drug-resin complex 9-Tulsion 255) ( $-\triangle-)$

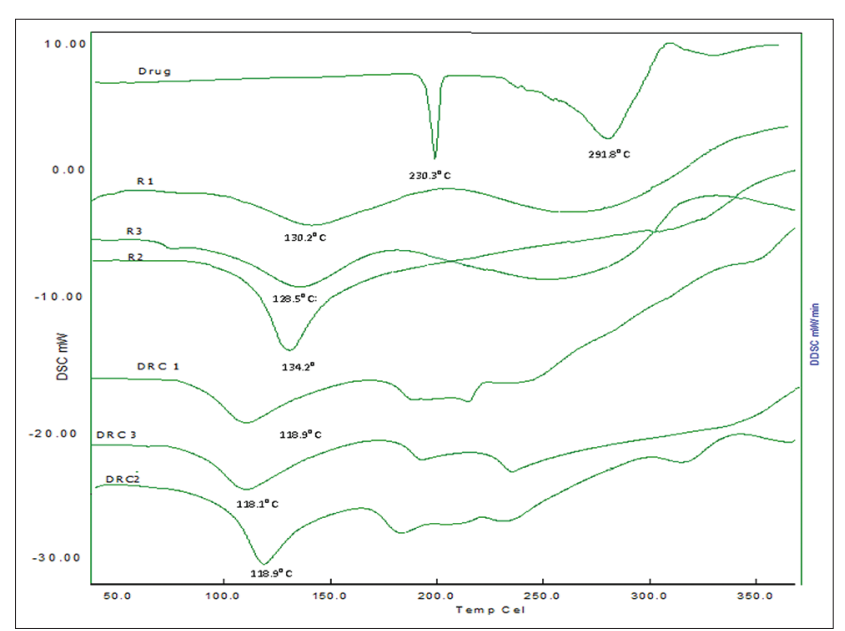

Fig. 2: The DSC thermograms of clarithromycin and thermograms of the drug-resinate mixtures. Drug-clarithromycin; R1-Indion; R2-Indion; R3-Tulsion; DRC3-Drug:resin Indion 204 (1:2); DRC6Drug:resin Indion 234 (1:2); DRC9-Drug:resin Tulsion 255 (1:2) 
All the prepared oral reconstituted suspensions (S1-S10) were subjected to evaluation. The ranges of viscosity was found to be $225.6 \pm 0.76-273.2 \pm 0.44 \mathrm{cps}$, $\mathrm{pH}$ was found to be $7.1 \pm 0.04-7.4 \pm 0.06$, sedimentation rate was found to be $0.95-0.99$ on $0^{\text {th }}$ day and $0.93-0.98$ on $7^{\text {th }}$ day, redispersibility was found to be + on $0^{\text {th }}$ day and + on $7^{\text {th }}$ day, and drug content was found to be $97.57 \pm 0.69-98.99 \pm 0.66 \%$, and particle size was found to be $97.89 \pm 0.57-168.97 \pm 0.97 \mu \mathrm{m}$.

All the formulations comprising DRC displayed rapid drug release when compared to S10 formulations. S3, S6, and S9 formulations exhibited a release $98.64 \pm 0.356 \%, 99.05 \pm 0.239 \%$, and $98.85 \pm 0.303 \%$ in $14 \mathrm{~min}$, respectively, other formulations exhibited release within 16-24 min. S10 formulations displayed a release of $98.02 \pm 0.432 \%$ after $24 \mathrm{~min}$ (Fig. 3). Thus, from the release studies, it was evident that the ionexchange resins can also act as dissolution enhancers apart from taste masking.

The threshold for the bitterness of clarithromycin was detected by varying its concentration, and threshold value was obtained from volunteers $(n=6)$ (Table 5). The reference points for standard bitterness and palatability are shown in Table 6.

Dunnett's test was performed to evaluate bitterness and overall acceptability of S1-S9 in comparison to S10 formulation without DRC (Table 7). Tukey's test was performed to evaluate bitterness and overall acceptability by selecting one formulation which was significantly different from each of the three groups, i.e., S3 (from group of S1, S2, and S3), S6 (from group of S4, S5, and S6), and S9 (from group of S7, S8, and S9), as shown in Table 8. The drug loading capacity of the resin was increased in acidic activated conditions than in alkaline activated conditions and this is due to the cationic nature of the used resin (Indion 204) since the COO- group of the Indion is loaded by $\mathrm{H}+$ of the acid but not $\mathrm{OH}-$ of the base. As the polymer concentration increased, the amount of drug-loaded onto all the resins also increased due to the stoichiometric exchange nature of the reaction in solution between drug and resin.

All the resins displayed an increase in drug loading capacity with an increase in swelling time; therefore, the time of swelling has to be established. The rate and extent of the ion-exchange process are increased if the resin is swollen and hydrated. In the unswollen resin matrix, the exchangeable groups are latent and remain coiled toward their backbone. Swelling increases the surface area and these groups are oriented toward outside. It was found that maximum drug loading was achieved within $6 \mathrm{~h}$ with an increase in the time of stirring the solution.

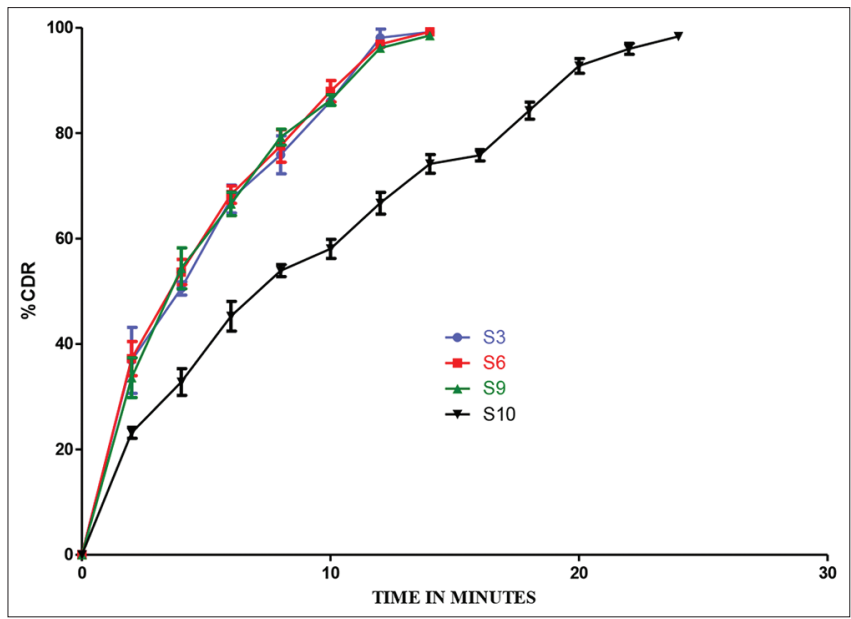

Fig. 3: In vitro cumulative percentage drug released from suspensions versus time. Optimized formulations versus control. Errors bars represent the standard deviation of $n=3, S 3(-\bullet-)$; S6 (一匹); S9 (- $-1-)$; S10 ( $-\nabla-)$
The effect of temperature on the exchange reactions showed that as the temperature rises, the exhaustive exchange zone is markedly shrunk, through which there is an increase in the ion diffusion rate. The percentage drug-loaded increased with increased $\mathrm{pH}$; this is due to the nature of the used resin and drugs where the ionization was favored at $\mathrm{pH}$ 8. The decreased complexation at higher $\mathrm{pH}$ is because at higher $\mathrm{pH}$, the solution becomes basic and cationic ion of resin gets saturated with the basic solution, thereby hindering the drug attachment. The decreased complexation at lower $\mathrm{pH}$ is because of an acidic environment the resin existed as a free acid in a non-ionic state and all the drug is released in the filtrate. The evaluated parameters were within the acceptable range. The in vitro dissolution studies were carried out for all the 9 DRC formulations and found to be excellent. The percentage drug released from 1:2 ratios of all the DRC was higher. The percentage of drug released from 1:2 ratio DRC6 of Indion 234

Table 7: Dunnett's test for bitterness, mouthfeel, and overall acceptability evaluation for all the formulations statistical data analysis

\begin{tabular}{|c|c|c|c|}
\hline $\begin{array}{l}\text { Dunnett's test } \\
\text { for bitterness }\end{array}$ & $\begin{array}{l}\text { Mean score } \\
\text { of } S 10 \pm S D\end{array}$ & $\begin{array}{l}\text { Mean scores } \\
\text { S1-S9 } \pm \text { SD }\end{array}$ & Summary \\
\hline $\mathrm{S} 10$ versus $\mathrm{S} 1$ & $3.83 \pm 0.4082$ & $2.16 \pm 0.408$ & $* * *$ \\
\hline S10 versus S2 & & $1.5 \pm 0.547$ & $* * *$ \\
\hline $\mathrm{S} 10$ versus S3 & & $0.33 \pm 0.516$ & $* * *$ \\
\hline S10 versus S4 & & $2.33 \pm 0.516$ & $* * *$ \\
\hline S10 versus S5 & & $1.33 \pm 0.516$ & $* * *$ \\
\hline S10 versus S6 & & $0.16 \pm 0.408$ & $* * *$ \\
\hline S10 versus S7 & & $2.16 \pm 0.408$ & $* * *$ \\
\hline S10 versus S8 & & $1.33 \pm 0.516$ & $* * *$ \\
\hline S10 versus S9 & & $0.16 \pm 0.408$ & $* * *$ \\
\hline $\begin{array}{l}\text { Dunnett's test } \\
\text { for mouthfeel }\end{array}$ & $\begin{array}{l}\text { Mean score } \\
\text { of } S 10 \pm S D\end{array}$ & $\begin{array}{l}\text { Mean scores } \\
\text { S1-S9 } \pm \text { SD }\end{array}$ & Summary \\
\hline $\mathrm{S} 10$ versus $\mathrm{S} 1$ & $2.00 \pm 0.6325$ & $2.00 \pm 0.632$ & ns \\
\hline $\mathrm{S} 10$ versus S2 & & $1.66 \pm 0.516$ & ns \\
\hline $\mathrm{S} 10$ versus S3 & & $2.00 \pm 0.894$ & ns \\
\hline S10 versus S4 & & $2.16 \pm 0.752$ & ns \\
\hline S10 versus S5 & & $1.83 \pm 0.752$ & ns \\
\hline S10 versus S6 & & $1.66 \pm 0.516$ & ns \\
\hline $\mathrm{S} 10$ versus S7 & & $1.83 \pm 0.752$ & ns \\
\hline S10 versus S8 & & $2.00 \pm 0.632$ & ns \\
\hline S10 versus S9 & & $1.83 \pm 0.752$ & ns \\
\hline $\begin{array}{l}\text { Dunnett's test } \\
\text { for flavor }\end{array}$ & $\begin{array}{l}\text { Mean score } \\
\text { of } S 10 \pm S D\end{array}$ & $\begin{array}{l}\text { Mean scores } \\
\text { S1-S9 } \pm \text { SD }\end{array}$ & Summary \\
\hline $\mathrm{S} 10$ versus $\mathrm{S} 1$ & $3.00 \pm 0.000$ & 0.408 & ns \\
\hline $\mathrm{S} 10$ versus S2 & & $3.33 \pm 0.516$ & ns \\
\hline $\mathrm{S} 10$ versus S3 & & $3.50 \pm 0.547$ & $*$ \\
\hline S10 versus S4 & & $3.66 \pm 0.516$ & $* *$ \\
\hline S10 versus S5 & & $4.00 \pm 0.000$ & $*$ \\
\hline S10 versus S6 & & $3.83 \pm 0.408$ & ns \\
\hline S10 versus S7 & & $2.83 \pm 0.752$ & ns \\
\hline S10 versus S8 & & $3.00 \pm 0.000$ & ns \\
\hline S10 versus S9 & & $3.00 \pm 0.000$ & ns \\
\hline $\mathrm{S} 10$ versus $\mathrm{S} 1$ & & $3.00 \pm 0.000$ & ns \\
\hline $\begin{array}{l}\text { Dunnett's test } \\
\text { for acceptability }\end{array}$ & $\begin{array}{l}\text { Mean score } \\
\text { of } S 10 \pm S D\end{array}$ & $\begin{array}{l}\text { Mean scores } \\
\text { S1-S9 } \pm \text { SD }\end{array}$ & Summary \\
\hline $\mathrm{S} 10$ versus $\mathrm{S} 1$ & $0.16 \pm 0.4082$ & $1.16 \pm 0.408$ & $* *$ \\
\hline $\mathrm{S} 10$ versus $\mathrm{S} 2$ & & $1.66 \pm 0.514$ & $* * *$ \\
\hline $\mathrm{S} 10$ versus S3 & & $3.50 \pm 0.547$ & $* * *$ \\
\hline $\mathrm{S} 10$ versus S4 & & $1.50 \pm 0.547$ & $* * *$ \\
\hline S10 versus S5 & & $2.16 \pm 0.400$ & $* * *$ \\
\hline S10 versus S6 & & $4.00 \pm 0.000$ & $* * *$ \\
\hline S10 versus S7 & & $1.16 \pm 0.408$ & $* *$ \\
\hline S10 versus S8 & & $1.33 \pm 0.516$ & $* * *$ \\
\hline S10 versus S9 & & $3.33 \pm 0.516$ & $* * *$ \\
\hline $\mathrm{S} 10$ versus $\mathrm{S} 1$ & & $1.16 \pm 0.408$ & $* *$ \\
\hline
\end{tabular}

${ }^{* * *} \mathrm{p}<0.001,{ }^{* *} \mathrm{p}<0.01,{ }^{*} \mathrm{p}<0.05,{ }^{\mathrm{n} s} \mathrm{p}=$ non-significant results are mean \pm standard deviation $(\mathrm{n}=3)$. SD: Standard deviation 
Table 8: Tukey's test for bitterness, mouthfeel, and overall acceptability evaluation for all the formulations statistical data analysis

\begin{tabular}{lll}
\hline \multicolumn{2}{l}{ Tukey's test for bitterness } & Summary \\
\hline S1 versus S2 & $2.16 \pm 0.408$ versus $1.50 \pm 0.547$ & ns \\
S1 versus S3 & $2.16 \pm 0.408$ versus $0.33 \pm 0.516$ & $* * *$ \\
S2 versus S3 & $1.50 \pm 0.547$ versus $0.33 \pm 0.516$ & $* *$ \\
S4 versus S5 & $2.33 \pm 0.516$ versus $1.33 \pm 0.516$ & $* *$ \\
S4 versus S6 & $2.33 \pm 0.516$ versus $0.16 \pm 0.408$ & $* * *$ \\
S5 versus S6 & $1.33 \pm 0.516$ versus $0.16 \pm 0.408$ & $* *$ \\
S7 versus S8 & $2.16 \pm 0.408$ versus $1.33 \pm 0.516$ & $*$ \\
S7 versus S9 & $2.16 \pm 0.408$ versus $0.16 \pm 0.408$ & $* * *$ \\
S8 versus S9 & $1.33 \pm 0.516$ versus $0.16 \pm 0.408$ & $* *$ \\
\hline Tukey's test for mouthfeel & Summary \\
\hline S1 versus S2 & $1.66 \pm 0.516$ versus $2.00 \pm 0.894$ & $\mathrm{~ns}$ \\
S1 versus S3 & $1.66 \pm 0.516$ versus $2.16 \pm 0.752$ & $\mathrm{~ns}$ \\
S2 versus S3 & $2.00 \pm 0.894$ versus $2.16 \pm 0.752$ & $\mathrm{~ns}$ \\
S4 versus S5 & $1.83 \pm 0.752$ versus $1.66 \pm 0.516$ & $\mathrm{~ns}$ \\
S4 versus S6 & $1.83 \pm 0.752$ versus $1.83 \pm 0.752$ & $\mathrm{~ns}$ \\
S5 versus S6 & $1.66 \pm 0.516$ versus $1.83 \pm 0.752$ & $\mathrm{~ns}$ \\
S7 versus S8 & $2.00 \pm 0.632$ versus $1.83 \pm 0.752$ & $\mathrm{~ns}$ \\
S7 versus S9 & $2.00 \pm 0.632$ versus $2.00 \pm 0.894$ & $\mathrm{~ns}$ \\
S8 versus S9 & $1.83 \pm 0.752$ versus $2.00 \pm 0.894$ & $\mathrm{~ns}$ \\
\hline
\end{tabular}

Tukey's test for flavor

$\mathrm{S} 1$ versus $\mathrm{S} 2$

$\mathrm{S} 1$ versus $\mathrm{S} 3$

$\mathrm{S} 2$ versus $\mathrm{S} 3$

$\mathrm{S} 4$ versus $\mathrm{S} 5$

S4 versus $\mathrm{S} 6$

S5 versus $\mathrm{S} 6$

$\mathrm{S} 7$ versus $\mathrm{S} 8$

S7 versus $\mathrm{S} 9$

S8 versus $\mathrm{S} 9$

$3.16 \pm 0.408$ versus $3.33 \pm 0.516$

$3.16 \pm 0.408$ versus $3.50 \pm 0.547$

$3.33 \pm 0.516$ versus $3.50 \pm 0.547$

$3.66 \pm 0.516$ versus $4.00 \pm 0.000$

$3.66 \pm 0.516$ versus $3.83 \pm 0.408$

$4.00 \pm 0.000$ versus $3.83 \pm 0.408$

$2.83 \pm 0.752$ versus $3.00 \pm 0.000$

$2.83 \pm 0.752$ versus $3.00 \pm 0.000$

$3.00 \pm 0.000$ versus $3.00 \pm 0.000$

Tukey's test for acceptability

$\mathrm{S} 1$ versus $\mathrm{S} 2$

$\mathrm{S} 1$ versus S3

$\mathrm{S} 2$ versus S3

$\mathrm{S} 4$ versus $\mathrm{S} 5$

$\mathrm{S} 4$ versus $\mathrm{S} 6$

$\mathrm{S} 5$ versus $\mathrm{S} 6$

S7 versus $\mathrm{S} 8$

$S 7$ versus $S 9$

S8 versus $\mathrm{S} 9$

$1.16 \pm 0.408$ versus $1.66 \pm 0.514$

$1.16 \pm 0.408$ versus $3.50 \pm 0.547$

$1.66 \pm 0.514$ versus $3.50 \pm 0.547$

$1.50 \pm 0.547$ versus $2.16 \pm 0.408$

$1.50 \pm 0.547$ versus $4.00 \pm 0.000$

$2.16 \pm 0.408$ versus $4.00 \pm 0.000$

$1.16 \pm 0.408$ versus $1.33 \pm 0.516$

$1.16 \pm 0.408$ versus $3.33 \pm 0.516$

$1.33 \pm 0.516$ versus $3.33 \pm 0.516$

Summary

ns

ns

ns

ns

ns

ns

ns

ns

ns

Summary

ns

$* *$

$* * *$

$* * *$

ns

$* * *$

$* * *$

${ }^{* * *} \mathrm{p}<0.001,{ }^{* *} \mathrm{p}<0.01,{ }^{*} \mathrm{p}<0.05,{ }^{\mathrm{ns}} \mathrm{p}=$ non-significant results are mean \pm standard deviation $(\mathrm{n}=3)$

(DRC6) was found to be higher. This is due to the presence of more exchangeable $\mathrm{H}+$ ions in the stomach causing the rapid exchange of similar ions in DRC thereby releasing the drug. DSC thermograms of clarithromycin showed sharp characteristic endothermic peaks which were not visible in the thermograms of the drug resinate mixtures (DRC3, DRC6, and DRC9), thereby indicating interaction and complex formation. All micrometric properties of the DRC were within the acceptable range. The formulations did display rapid drug release, but enhanced drug dissolution was observed in S3, S6, and S9 formulation due to a higher ratio of drug to resin (1:2). The taste evaluation test showed that the DRC concentration (1:2) of the formulations showed that there was no release in saliva thereby satisfactorily masking the bitter taste. In the case of Dunnett's test for bitterness and overall acceptability evaluation, S1-S9 when compared to S10 gave $\mathrm{p}<0.001$. Hence, all the formulations are significant when compared to S10. In case of Tukey's test for bitterness and overall acceptability, evaluation was carried out by selecting one formulation which was highly statistically significant from each of the three groups, i.e., S3 (from group of S1, S2, and S3), S6 (from group of S4, S5, and S6), and S9 (from group of S7, S8, and S9). Hence, all three formulations possess good taste masking of the drug and good overall acceptability. S6 was widely accepted by the volunteers. In the case of Dunnett's test and Tukey's test for mouthfeel evaluation, S1-S9 when compared to S10 showed no significant difference. Hence, all the formulations have significantly same mouthfeel when compared to S10. This concludes that the addition of resins to the formulation did not alter the mouthfeel of the suspensions. From the above data, it can be concluded that ionexchange complexation of clarithromycin with Indion 204, Indion 234, and Tulsion 335 could efficiently mask the bitter taste and achieve palatable taste suitable for pediatric use.

\section{CONCLUSION}

Taste masking could be effectively achieved by the use of ion-exchange resins as it was found to be a safe, commercially inexpensive and easy method to achieve taste-masked complex of a bitter drug with a smooth feel. The taste-masked complex was successfully developed as an oral reconstituted suspension that can be considered as the geriatric and pediatric friendly dosage form.

\section{ACKNOWLEDGMENT}

The authors express deep gratitude to Ind-Swift Laboratories Limited, Punjab, for providing the gift sample of the drug Clarithromycin and Ion Exchange India Ltd., Mumbai, for Indion 204 and Indion 234 and Thermax Ltd., Pune, for Tulsion-335. The authors are also immensely grateful to Dr. M.G.R. Educational and Research Institute, Velappanchavadi, for providing all the facilities required to carry out the research work.

\section{AUTHORS' CONTRIBUTIONS}

All authors contributed equally.

\section{CONFLICTS OF INTEREST}

There are no conflicts of interest.

\section{AUTHORS FUNDING}

No funding was provided for this research.

\section{REFERENCES}

1. Sharma S, Lewis S. Taste masking technologies: A review. Int J Pharm Pharm Sci 2010;2:6-13.

2. Sohi H, Sultana Y, Khar RK. Taste masking technologies in oral pharmaceuticals: Recent developments and approaches. Drug Dev Ind Pharm 2004;30:429-48.

3. Roy GM, editor. Modifying Bitterness: Mechanism, Ingredients, and Applications. Boca Raton, Florida: CRC Press; 1997.

4. Borodkin S, Sundberg DP. Polycarboxylic acid ion-exchange resin adsorbates for taste coverage in chewable tablets. J Pharm Sci 1971;60:1523-7.

5. Borodkin S, Yunker $\mathrm{MH}$. Interaction of amine drugs with a polycarboxylic acid ion-exchange resin. J Pharm Sci 1970;59:481-6.

6. Rajesh MA, Bhatt SA, Ramana GV, Brahmbhatt H, Gajjar K, Tripathi CR, et al. Taste masking by functional cross-linked copolymers and sustain release of drug through interpenetrating polymer network with sodium alginate and k-carreganeen biopolymers. Int J Pharm Pharm Sci 2014;6:352-9.

7. Anand V, Kandarapu R, Garg S. Ion-exchange resins: Carrying drug delivery forward. Drug Discov Today 2001;6:905-14.

8. Borodkin S. Ion exchange resins delivery systems. In: Tarcha PJ, editors. Polymers for Drug Delivery. $1^{\text {st }}$ ed. Boca Raton: CRC Press; 1991. p. 215-30.

9. Venkateswaramurthy N, Sambathkumar R, Vijayabaskaran M, Perumal P. Clarithromycin mucoadhesive microspheres for antiHelicobacter pylori therapy: Formulation and in vitro evaluation. Int $\mathrm{J}$ Curr Pharm Res 2010;2:24-7.

10. Lu MY, Borodkin S, Woodward L, Li P, Diesner C, Hernandez L, et al. A polymer carrier system for taste masking of macrolide antibiotics. Pharm Res 1991;8:706-12.

11. Yu X, Liu H, Sun C, Shi S, Fu X, He Y. A simple and novel method for preparing the taste masking levofloxacin microsphere suspension. Afr J Pharm Pharmacol 2012;6:1617-24. 
12. Goyal A, Singhvi I. Visible spectrophotometric methods for estimation of clarithromycin from tablet formulation. Indian $\mathrm{J}$ Pharm Sci 2006;68:656-7.

13. Helmy A, Kady ES, Khames A, Abd-elbary A. Preparation, characterization and in-vitro/vivo evaluation of Indion-based chewable tablets of paracetamol and ibuprofen for pediatric use. J Am Sci 2011;7:831-44.

14. Yewale CP, Rathi MN, Kore GG, Jadhav GV, Wagh MP. Formulation and development of taste masked fast-disintegrating tablets (FDTs) of chlorpheniramine maleate using ion-exchange resins. Pharm Dev Technol 2013;18:367-76.

15. Dahima R, Sharma R. Comparitive study of ion exchange resin Indion 204 and Indion 214 for taste masking of metoclopramide hydrochloride and formulation of rapid disintegrating tablets. Asian J Pharm 2010;4:110-5.

16. Jain DK, Darwhekar GN, Choudhary N. Formulation and evaluation of reconstitutable oral suspension of ambroxol $\mathrm{HCl}$ and azithromycin. Int J PharmTech Res 2011;3:741-6.

17. Shanbhag PP, Bhalerao SS. Development and evaluation of oral reconstitutable systems of cephalexin. Int $J$ PharmTech Res 2010;2:502-6.

18. Sana S, Rajani A, Sumedha N, Mahesh B. Formulation and evaluation of taste masked oral suspension of dextromethorphan hydrobromide. Int J Drug Dev Res 2012;4:159-72.

19. Devrim B, Bozkir A, Canefe K. Formulation and evaluation of reconstitutable suspensions containing ibuprofen-loaded eudragit microspheres. Acta Pol Pharm 2011;68:593-9.

20. Ishizaka T, Okada S, Takemoto E, Tokuyama E, Tsuji E, Mukai J, et al. The suppression of enhanced bitterness intensity of macrolide dry syrup mixed with an acidic powder. Chem Pharm Bull (Tokyo) 2007;55:1452-7.

21. Oza N, Sagar S. Design and optimization of pediatric cefuroxime axetil dispersible tablet containing ion-exchange resin. Int J Appl Pharm 2019;11:325-32.

22. Pawar HA, Joshi PR. Development and evaluation of taste masked granular formulation of satranidazole by melt granulation technique. J Pharm 2014;2014:1-7.

23. Tavakoli N, Ghodrati M, Ghassemi-Dehkordi N, Sadeghi-Aliabadi H. Formulation and evaluation of a new herbal tablet from strawberry and grape leaves. Jundishapur J Nat Pharm Prod 2008;3:19-25.

24. Dasankoppa FS, Komal S, Sholapur HN, Nanjundaswamy NG, Sajjanar VM. Design, optimization and evaluation of chewable tablets of clarithromycin using ion exchange resins. Indian J Pharm Sci 2016;78:818-26. 
PICTORIAL ABSTRACT

COMPLEXATION

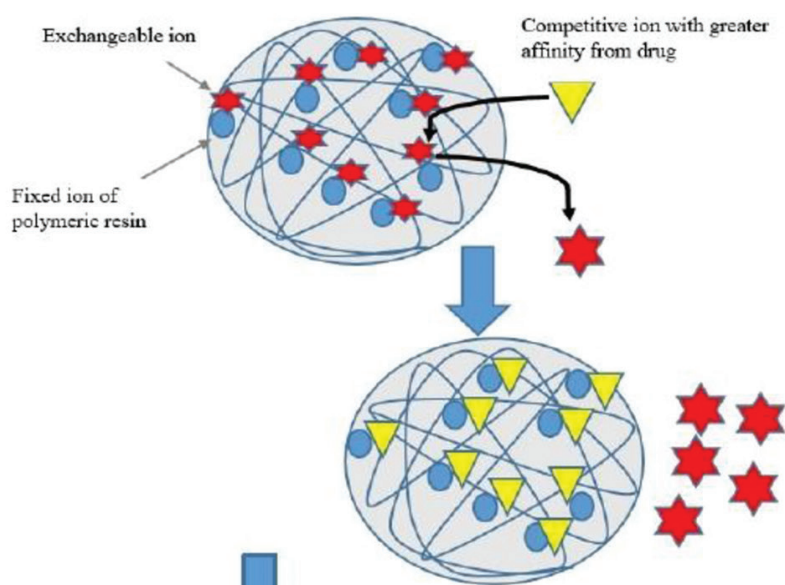

\section{DRC EVALUATION}
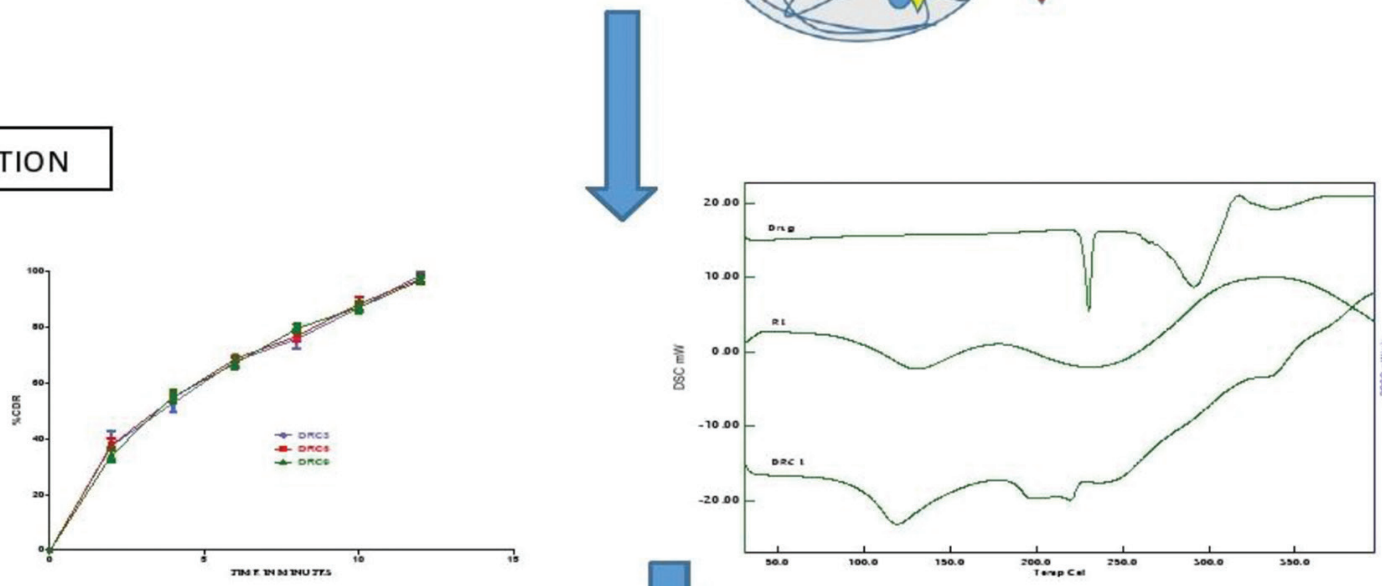

FORMULATION, EVALUATION AND STATISTICAL

PREFERENCE OF WIDELY ACCEPTED FORMULATION
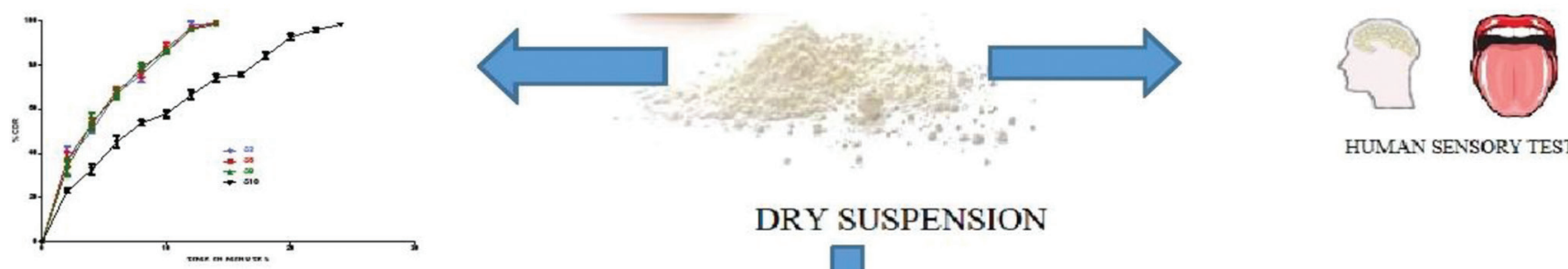

HUMAN SENSORY TEST

DRY SUSPENSION

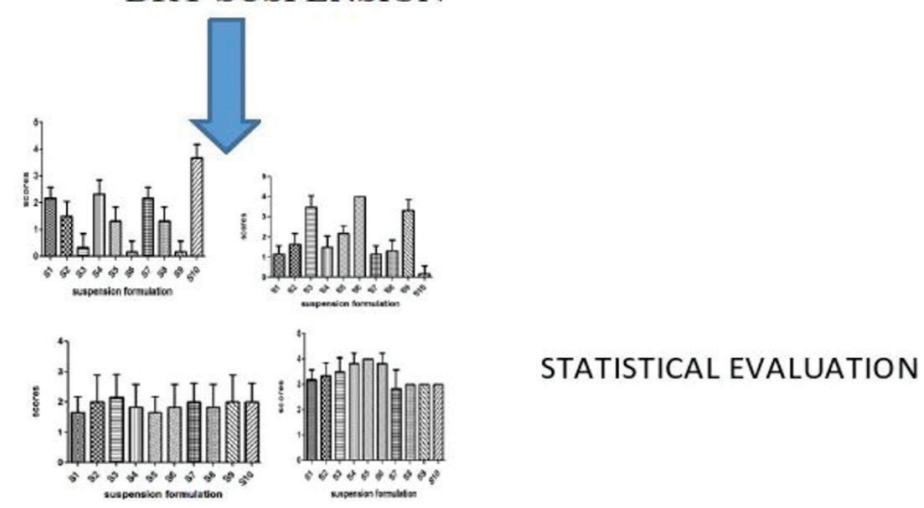

